\title{
Eradication of the invasive, exotic tree Senna spectabilis in the Mahale Mountains
}

\author{
$\operatorname{AUTHOR}(S)$ :
}

Nishida, Toshisada

\section{CITATION:}

Nishida, Toshisada. Eradication of the invasive, exotic tree Senna spectabilis in the Mahale Mountains. Pan Africa News 1996, 3(2): 6-7

\section{ISSUE DATE:}

1996-12

URL:

http://hdl.handle.net/2433/143343

\section{RIGHT:}

Copyright (C) Pan Africa News. 


\title{
Eradication of the invasive, exotic tree Senna spectabilis in the Mahale Mountains
}

\author{
Toshisada Nishida, Professor \\ Kyoto University
}

For over a decade we have noted the invasion of Senna (formerly Cassia) spectabilis trees into lowland areas of the Mahale Mountains National Park. In an attempt to eradicate the trees I asked our assistants to cut or girdle them on more than one occasion. Later, park management also carried out the same work on a larger scale. Despite our attempts to deal with the problem, however, the exotic species still prospers within the park.

Mr. C.K. Ruffo, a botanist with the National Tree Seed Programme, Morogoro, made a 3-day survey in February 1995 at park management request to identify the trees and assess the extent of the problem. Ruffo (3) concluded that $S$. spectabilis was threatening to colonize the entire area occupied by lowland and montane rain forest in Mahale National Park.

From the perspective of the creation of park policy (1), the $S$. spectabilis invasion should be among the most serious problems for management to tackle. Team members of the Mahale Mountains Chimpanzees Research Project 
have also started to address the issue in terms of the impact of the invasion on wildlife and the native vegetation $(4,5$, 6).

We decided to incorporate this problem in our chimpanzee research project as a formal research topic in 1995 and asked Mr. James Wakibara, a park ecologist, join us as a member of our research team and to make test plots (perhaps $10 \mathrm{~m} \times 10 \mathrm{~m}$ each) in order to comparatively analyse the influences of various types of artificial intervention on the ecology, growth and spread of Senna spectabilis.

Such plots would consist of four treatments: 1) control (no intervention), 2) girdling/cutting trees, 3) cutting trees and removing seeds from the ground, 4) planting larger saplings of some pioneer chimpanzee food trees (2).

The fact that previous attempts to control the trees were unsuccessful does not necessarily mean they cannot be used to control the Senna. Cutting $S$. spectabilis when it flowers and girdling in the dry season might prove more effective. Removing seed pods from the forest immediately after they fall to the ground before seeds are released should be attempted next season in order to prevent seeds from germinating. I would also suggest a practical solution to both park and community conservation by regular cutting and exportation of the largest Senna trees to neighboring villages where building materials and fuel are in short supply.

Understanding the ecology of Senna in its introduced range will be essential for devising an effective plan for the restoration of chimpanzee habitat at Mahale. Team members are currently analysing data collected during recent visits to Mahale, including soil samples and tree cores. At the IPS conference in Wisconsin this summer, where Turner \& Golinski presented preliminary results of their study on Senna, Chris Bakuneeta, a researcher at Budongo Forest Reserve in Uganda, noted that Senna has also invaded chimpanzee habitat at his study site and is interested in cooperative research with Mahale scientists to understand the ecology of this exotic species.

I want to point out the positive aspects of the $S$. spectabilis invasion in regards to its implications for community conservation. If we can understand the invasion of Senna in some areas of the park, we could apply this knowledge to resource conservation outside the park. $S$. spectabilis, because of its rapid growth, could potentially play an important role as a provider of badly needed construction materials to village communities if planted in those areas. Thus, the study of $S$. spectabilis would be doubly important in contributing both to park management and community conservation.

We would like to thank ANC Productions (Tokyo), our long-term partner in the documentation of our scientific investigation of wild chimpanzees, for their financial support of Mr. Wakibara's efforts at Mahale. We also plan to apply for additional funds to support an effective $S$. spectabilis eradication program. Hopefully, our joint efforts will arrive at a solution to the invasion of this exotic species in the near future.

\section{References}

1. Anonymous, 1994. National Policies for National Parks in Tanzania. Tanzania National Parks National Policy Committee.

2. Nishida, T. \& S. Uehara, 1983. Natural diet of chimpanzees (Pan troglodytes schweinfurthii): Long-term record from the Mahale Mountains, Tanzania. Afr. Study Monogr. 3: 109-130.

3. Ruffo, C.K. 1995. A Report on the Identification and Invasion of Senna spectabilis in Mahale National Park, Tanzania. A document presented to TANAPA in April, 1995.

4. Turner, L.A. 1995. Alien tree species invasive in Mahale Mountains National Park, Tanzania. Mahale Mountains Chimpanzee Research Project Ecological Report No.99.

5. Turner, L.A. 1996. Invasive plant in chimpanzee habitat at Mahale. Pan Africa News 3(1):5.

6. Turner, L.A. \& K. Golinski, in prep. A preliminary assessment of Senna spectabilis, an invasive tree in secondary vegetation at Mahale Mountains National Park, Tanzania. 